\title{
Morphology and Optical Property of ZnO Nanostructures Grown by Solvothermal Method: Effect of the Solution Pretreatment
}

\author{
Wenhui Zhang, ${ }^{1,2}$ Xiahui Chen, ${ }^{3}$ Ning Xu, ${ }^{1}$ Rong Xiang, ${ }^{2}$ Yuan Zhu, ${ }^{2}$ and Zikang Tang ${ }^{2,4}$ \\ ${ }^{1}$ New Environmental Protection Key Laboratory of Jiangsu Province, Yancheng Institute of Technology, Yancheng 224051, China \\ ${ }^{2}$ State Key Lab of Optoelectronic Materials and Technologies, School of Physics and Engineering, Sun Yat-sen University, \\ Guangzhou 510006, China \\ ${ }^{3}$ School of Microelectronics and Solid-State Electronics, University of Electronic Science and Technology of China, \\ Shahe Campus, Chengdu 610054, China \\ ${ }^{4}$ Physics Department, Hong Kong University of Science and Technology, Clear Water Bay, Kowloon, Hong Kong
}

Correspondence should be addressed to Wenhui Zhang; zwhuizi000@sina.com

Received 1 April 2013; Accepted 23 July 2013

Academic Editor: Pathik Kumbhakar

Copyright (c) 2013 Wenhui Zhang et al. This is an open access article distributed under the Creative Commons Attribution License, which permits unrestricted use, distribution, and reproduction in any medium, provided the original work is properly cited.

\begin{abstract}
Zinc oxide $(\mathrm{ZnO})$ nanostructures with different morphologies such as nanopyramids, nanosheets, and nanoparticles have been grown by a simple solvothermal method. The influence of solution pretreatmentt on the morphology and optical properties of $\mathrm{ZnO}$ nanostructures has been studied. The experimental results revealed the morphology of $\mathrm{ZnO}$ transformed from nanopyramids or nanosheets to nanoparticles after solution pretreatment. Raman and photoluminescence spectra are recorded to examine the crystallinity and optical property of the samples.
\end{abstract}

\section{Introduction}

$\mathrm{ZnO}$ has been recognized as one of the most important IIVI compound semiconductor materials in scientific research and technological applications, owing to its wide direct bandgap $(3.37 \mathrm{eV})$, large exciton binding energy $(60 \mathrm{~m} \mathrm{eV})$ at room temperature $[1,2]$, noncentrosymmetric structures, and various shape-induced functions. Compared to the bulk material, $\mathrm{ZnO}$ nanostructures have a wide range of applications including catalysts [3], piezoelectric devices [4], optoelectronic devices [5], photovoltaic cells [6], and gas sensors $[7,8]$ due to their unique physical and chemical properties. In recent years, lots of research has been focused on the synthesis, characteristics, growth mechanism, device fabrication, and performance improvement of $\mathrm{ZnO}$ nanostructures with various morphologies including nanowires [9], nanorods [10], nanobelts [11], nanotubes [12], nanosheets [13, 14], nanopyramids $[15,16]$, hollow nanospheres [17], and quantum dots [18], which have been fabricated via different methods, such as chemical vapor deposition, sol-gel method, hydrothermal method, and solvothermal method [19-22].
Among these, relatively little is known about the controlled synthesis of the different morphologies of $\mathrm{ZnO}$ simply by adjusting the synthetic conditions. In this work, we have investigated the influence of solution pretreatment on morphology and optical properties of $\mathrm{ZnO}$ nanostructures grown by solvothermal process.

\section{Materials and Methods}

Zinc acetate dihydrate $\left(\mathrm{Zn}(\mathrm{OAc})_{2} \cdot 2 \mathrm{H}_{2} \mathrm{O}\right.$, Sinopharm Chemical Reagent Co., Ltd.), zinc nitrate hydrate $\left(\mathrm{Zn}\left(\mathrm{NO}_{3}\right)_{2} \cdot 6 \mathrm{H}_{2} \mathrm{O}\right.$, Sinopharm Chemical Reagent Co., Ltd.), oleylamine (OM, 96\%, J\&K Scientific Ltd.), and dodecanol (DDL, 98\%, Acros Organics) used in the experiments were of analytical purity. Typically, $0.5 \mathrm{mmol} \mathrm{Zn}(\mathrm{OAc})_{2} \cdot 2 \mathrm{H}_{2} \mathrm{O}$ or $\mathrm{Zn}\left(\mathrm{NO}_{3}\right)_{2} \cdot 6 \mathrm{H}_{2} \mathrm{O}$ was added to a mixed solvent composed of $3 \mathrm{~mL} \mathrm{OM}$ and $6 \mathrm{~mL} \mathrm{DDL}$ at room temperature. The resulting slurry was heated to $120^{\circ} \mathrm{C}$ in a vacuum to remove water for solution pretreatment. The resulting mixture was transferred into a Teflon-lined stainless steel autoclave $(20 \mathrm{~mL})$ for solvothermal synthesis at $180^{\circ} \mathrm{C}$ for $2 \mathrm{~h}$ in an electric oven. After the 
reaction, the autoclave was cooled and the $\mathrm{ZnO}$ products were centrifuged, rinsed several times with ethanol in order to remove the residual reactants, and dispersed in cyclohexane.

Powder X-ray diffraction (XRD) analyses were performed on a D-MAX 2200 VPC X-ray diffractometer with $\mathrm{Cu} \mathrm{K} \alpha$ irradiation $(\lambda=1.5406 \AA)$ at a scanning speed of $0.014^{\circ} / \mathrm{sec}$ over the $2 \theta$ range of $20-60^{\circ}$. The electronic morphology of the samples was examined by Hitachi S- 4800 scanning electron microscope (SEM) and FEI Tecnai G2 Spirit transmission electron microscope (TEM). Photoluminescence (PL) spectra of samples were recorded using Jobin-Yvon Lab-Ram high-resolution spectrometer with $\mathrm{He}-\mathrm{Cd}$ laser with the wavelength $325 \mathrm{~nm}$. Raman spectra of samples were recorded using Jobin-Yvon Lab-Ram high-resolution spectrometer with laser of wavelength $633 \mathrm{~nm}$.

\section{Results and Discussion}

The powder X-ray diffraction (XRD) patterns of the assynthesized samples are shown in Figure 1. The XRD patterns of the samples using $\mathrm{Zn}(\mathrm{OAc})_{2} \cdot 2 \mathrm{H}_{2} \mathrm{O}$ and $\mathrm{Zn}\left(\mathrm{NO}_{3}\right)_{2} \cdot 6 \mathrm{H}_{2} \mathrm{O}$ as raw materials indicate a pure hexagonal wurtzite-type $\mathrm{ZnO}$ phase (JCPDS number 75-1526) and (JCPDS number 05-664) with high crystallinity, respectively.

The SEM images of the as-synthesized samples are shown in Figure 2. When $\mathrm{Zn}(\mathrm{OAc})_{2} \cdot 2 \mathrm{H}_{2} \mathrm{O}$ was used as raw material, the samples without solution pretreatment have a pyramidal morphology with an average size of $\sim 170 \mathrm{~nm}$ (side-edge length). The trigonal and hexagonal particle shapes observed in the TEM image thus correspond to the side-view projections of the pyramids. After solution pretreatment, the samples were transformed into nanoparticles with the average diameter of $\sim 27 \mathrm{~nm}$. When $\mathrm{Zn}\left(\mathrm{NO}_{3}\right)_{2} \cdot 6 \mathrm{H}_{2} \mathrm{O}$ was used as raw material, the samples without solution pretreatment have a nanosheet morphology with an average size of $\sim 55 \mathrm{~nm}$. The thickness of nanosheet was about $15 \mathrm{~nm}$. After solution pretreatment, the samples were also transformed into nanoparticles with the average diameter of $\sim 26 \mathrm{~nm}$. From the above experimental results, a possible mechanism can be deduced. The OM-DDL mixture played a key role in the formation of different $\mathrm{ZnO}$ nanostructures. The 001 plane is the most rapid growth rate plane during the crystal planes of hexagonal structure $\mathrm{ZnO}$ and is the preferred growth direction. When $\mathrm{Zn}(\mathrm{OAc})_{2} \cdot 2 \mathrm{H}_{2} \mathrm{O}$ was used as raw material, the OM-DDL mixture could result in strong electrostatic interaction with the polar surfaces of the growing $\mathrm{ZnO}$ nanocrystals thus resulting in decreasing the surface energy of polar surfaces and hence slowing down the growth rate of the polar planes. This could result in the polar plane being the exposed basal surface of the nanopyramid which grows slowly with welldeveloped facets [23]. When $\mathrm{Zn}\left(\mathrm{NO}_{3}\right)_{2} \cdot 6 \mathrm{H}_{2} \mathrm{O}$ was used as raw material, the intrinsically anisotropic growth of $\mathrm{ZnO}$ along the 001 direction is substantially suppressed and crystal growth then proceeds sideways, which results in the formation of $\mathrm{ZnO}$ nanosheets. Pretreatment of solution may reduce suppressing effect in the growth of $\mathrm{ZnO}$ nanocrystals, leading to the formation of nanoparticles.

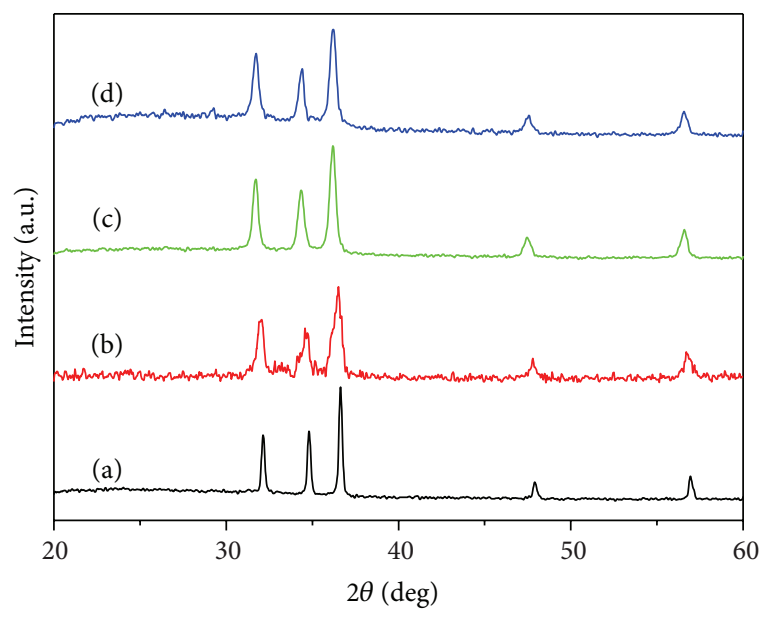

FIGURE 1: XRD patterns of the as-synthesized samples (a) without and (b) with solution pretreatment using $\mathrm{Zn}(\mathrm{OAc})_{2} \cdot 2 \mathrm{H}_{2} \mathrm{O}$ as raw material and (c) without and (d) with solution pretreatment using $\mathrm{Zn}\left(\mathrm{NO}_{3}\right)_{2} \cdot 6 \mathrm{H}_{2} \mathrm{O}$ as raw material.

Raman spectra of $\mathrm{ZnO}$ samples using $633 \mathrm{~nm}$ laser are shown in Figure 3. $\mathrm{E}_{2}$ (low) mode at $99 \mathrm{~cm}^{-1}$ and $\mathrm{E}_{2}$ (high) mode at $437 \mathrm{~cm}^{-1}$ dominate in the Raman scattering spectra, indicating that all the samples had perfect crystal quality. The peak at $331 \mathrm{~cm}^{-1}$ can be attributed to the $\mathrm{E}_{2}$ (high)- $\mathrm{E}_{2}$ (low) mode of $\mathrm{ZnO}$, which is assigned to the second-order Raman spectrum arising from zone-boundary phonons of the hexagonal $\mathrm{ZnO}[24,25]$.

Figure 4 shows the room temperature PL spectrum of the samples with using $325 \mathrm{~nm}$ laser. There are two emission bands in the PL spectrum: a strong and narrow near UV emission at $381 \mathrm{~nm}$ and a broad but weak spectral band ranging from 450 to $600 \mathrm{~nm}$. The near UV peak is due to the recombination of electron and hole in an exciton, while the visible emission is due to the presence of various point defects, such as interstitial oxygen and oxygen vacancies. In this work, the visible emission of $\mathrm{ZnO}$ nanopyramids and nanosheets is stronger than that of $\mathrm{ZnO}$ nanoparticles, suggesting that the content of oxygen vacancy in $\mathrm{ZnO}$ nanopyramids and nanosheets is larger than that in $\mathrm{ZnO}$ nanoparticles. The observation of such a strong emission band from excitons rather than from defects might imply that the samples hold high crystallinity or low lattice disorder, specially after solution pretreatment.

\section{Conclusions}

$\mathrm{ZnO}$ nanostructures have been grown by solvothermal method. The solution pretreatment is a key factor in the morphological control of $\mathrm{ZnO}$ nanostructures. The morphology of $\mathrm{ZnO}$ transformed from nanopyramids or nanosheets to nanoparticles by solution pretreatment. The process is simple and leads to highly crystalline particles with controllable morphology. The growth mechanism is discussed. $\mathrm{ZnO}$ nanopyramids, nanosheets, and nanoparticles exhibit excellent emission properties. 


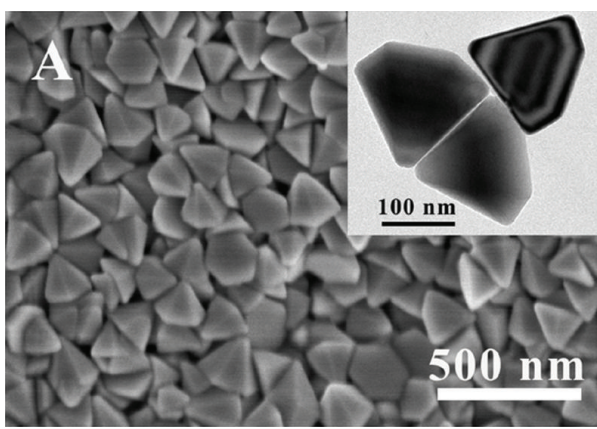

(a)

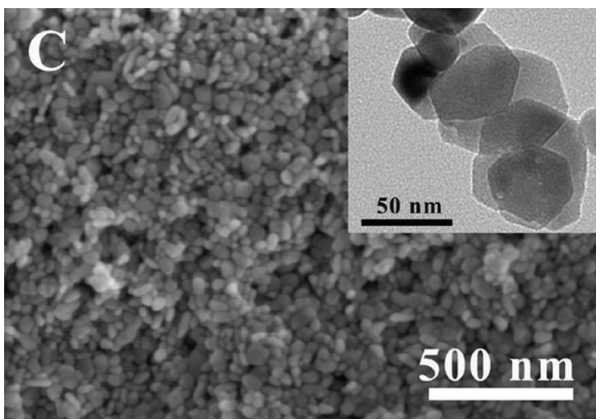

(c)

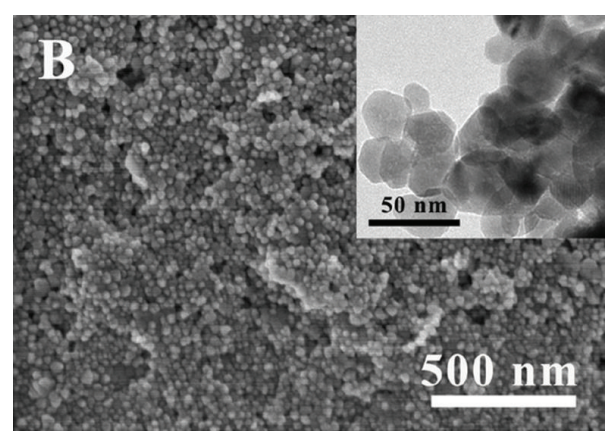

(b)

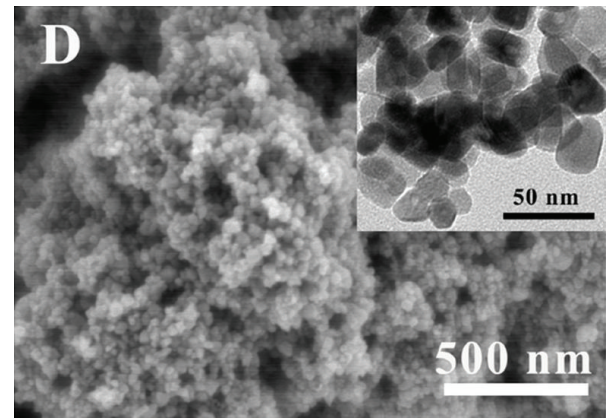

(d)

FIGURE 2: SEM images of the samples (a) without and (b) with solution pretreatment using $\mathrm{Zn}(\mathrm{OAc})_{2} \cdot 2 \mathrm{H}_{2} \mathrm{O}$ as raw material and (c) without and (d) with solution pretreatment using $\mathrm{Zn}\left(\mathrm{NO}_{3}\right)_{2} \cdot 6 \mathrm{H}_{2} \mathrm{O}$ as raw material. Inset: TEM images of the corresponding sample.

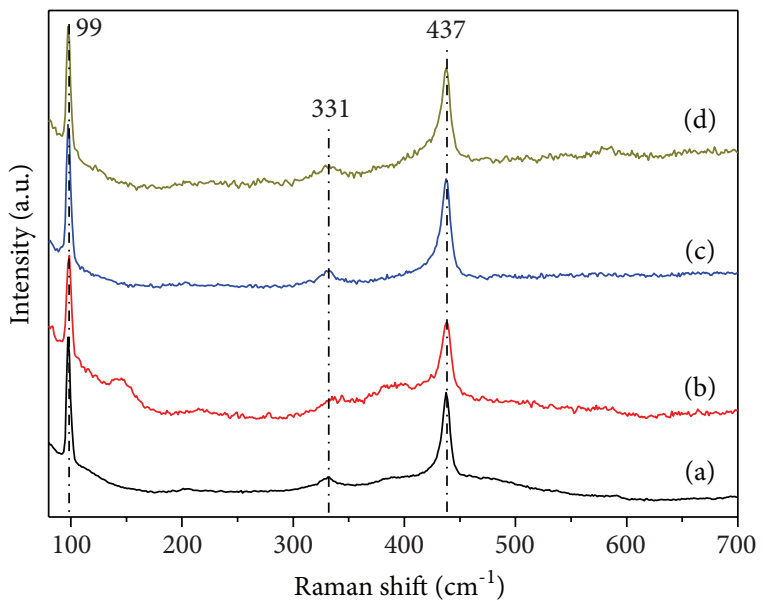

FIGURE 3: Raman spectra of the samples (a) without and (b) with solution pretreatment using $\mathrm{Zn}(\mathrm{OAc})_{2} \cdot 2 \mathrm{H}_{2} \mathrm{O}$ as raw material and (c) without and (d) with solution pretreatment using $\mathrm{Zn}\left(\mathrm{NO}_{3}\right)_{2} \cdot 6 \mathrm{H}_{2} \mathrm{O}$ as raw material.

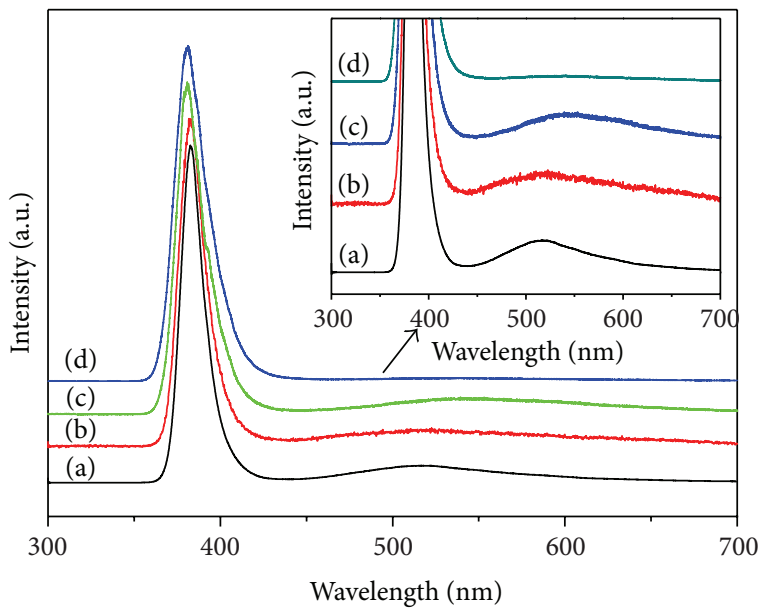

FIGURE 4: PL spectra of the samples (a) without and (b) with solution pretreatment using $\mathrm{Zn}(\mathrm{OAc})_{2} \cdot 2 \mathrm{H}_{2} \mathrm{O}$ as raw material and (c) without and (d) with solution pretreatment using $\mathrm{Zn}\left(\mathrm{NO}_{3}\right)_{2} \cdot 6 \mathrm{H}_{2} \mathrm{O}$ as raw material. Inset: Partial enlarged drawing of PL spectra.

\section{Acknowledgment}

We gratefully acknowledge the financial aids from the China Postdoctoral Science Foundation funded project (Grant no. 2012300004109568) and National Key Technology R\&D Program of China (Grant no. 2013BAC13B01).

\section{References}

[1] M. H. Huang, S. Mao, H. Feick et al., "Room-temperature ultraviolet nanowire nanolasers," Science, vol. 292, no. 5523, pp. 18971899, 2001.

[2] P. D. Yang, H. Q. Yan, S. Mao et al., "Controlled growth of $\mathrm{ZnO}$ nanowires and their optical properties," Advanced Functional Materials, vol. 12, no. 5, pp. 323-331, 2002. 
[3] X. Wang, M. Y. Liao, Y. T. Zhong et al., "ZnO hollow spheres with double-yolk egg structure for high-performance photocatalysts and photodetectors," Advanced Materials, vol. 24, no. 25, pp. 3421-3425, 2012.

[4] Z. L. Wang and J. Song, "Piezoelectric nanogenerators based on zinc oxide nanowire arrays," Science, vol. 312, no. 5771, pp. 243246, 2006.

[5] J. H. He, J. J. Ke, P. H. Chang et al., "Development of Ohmic nanocontacts via surface modification for nanowire-based electronic and optoelectronic devices: $\mathrm{ZnO}$ nanowires as an example," Nanoscale, vol. 4, no. 11, pp. 3399-3404, 2012.

[6] Y. T. Shi, C. Zhu, L. Wang et al., "Optimizing nanosheet-based $\mathrm{ZnO}$ hierarchical structure through ultrasonic-assisted precipitation for remarkable photovoltaic enhancement in quasi-solid dye-sensitized solar cells," Journal of Materials Chemistry, vol. 22, no. 26, pp. 13097-13103, 2012.

[7] L. Wang, Y. Kang, X. Liu, S. Zhang, W. Huang, and S. Wang, "ZnO nanorod gas sensor for ethanol detection," Sensors and Actuators B, vol. 162, no. 1, pp. 237-243, 2012.

[8] W. Zhang, W. Zhang, and J. Zhou, "Solvent thermal synthesis and gas-sensing properties of Fe-doped $\mathrm{ZnO}$," Journal of Materials Science, vol. 45, no. 1, pp. 209-215, 2010.

[9] S. Z. Yang, L. F. Wang, X. Z. Tian et al., "The piezotronic effect of Zinc oxide nanowires studied by in situ TEM," Advanced Materials, vol. 24, no. 34, pp. 4676-4682, 2012.

[10] W. Zhang, W. Zhang, and X. Ma, “Tunable ZnO nanostructures for ethanol sensing," Journal of Materials Science, vol. 44, no. 17, pp. 4677-4682, 2009.

[11] Y. Yang, G. Wang, and X. Li, "Water molecule-induced stiffening in ZnO nanobelts," Nano Letters, vol. 11, no. 7, pp. 28452848, 2011.

[12] Z. Liang, H. Cui, K. Wang et al., "Morphology-controllable ZnO nanotubes and nanowires: synthesis, growth mechanism and hydrophobic property," CrystEngComm, vol. 14, no. 5, pp. 17231728, 2012.

[13] H. Li, Y. Zhang, and J. Wang, "ZnO nanosheets derived from surfactant-directed process: growth mechanism, and application in dye-sensitized solar cells," Journal of the American Ceramic Society, vol. 95, no. 4, pp. 1241-1246, 2012.

[14] H. Yan, Z. Yu, K. Lu, Y. Zhang, and Z. Wei, "Self-assembly of graphenelike $\mathrm{ZnO}$ superstructured nanosheets and their application in hybrid photoconductors," Small, vol. 7, no. 24, pp. 3472-3478, 2011.

[15] P. Li, Z. Wei, T. Wu, Q. Peng, and Y. Li, "Au-ZnO hybrid nanopyramids and their photocatalytic properties," Journal of the American Chemical Society, vol. 133, no. 15, pp. 5660-5663, 2011.

[16] K. X. Yao, X. Liu, L. Zhao, H. C. Zeng, and Y. Han, "Site-specific growth of Au particles on $\mathrm{ZnO}$ nanopyramids under ultraviolet illumination," Nanoscale, vol. 3, no. 10, pp. 4195-4200, 2011.

[17] C. Q. Zhu, B. A. Lu, Q. Su et al., "A simple method for the preparation of hollow $\mathrm{ZnO}$ nanospheres for use as a high performance photocatalyst," Nanoscale, vol. 4, no. 10, pp. 3060-3064, 2012.

[18] D. A. Firmansyah, S. Kim, K. Lee, R. Zahaf, Y. H. Kim, and D. Lee, "Microstructure-controlled aerosol-gel synthesis of $\mathrm{ZnO}$ quantum dots dispersed in $\mathrm{SiO} 2$ nanospheres," Langmuir, vol. 28, no. 5, pp. 2890-2896, 2012.

[19] J. E. Stehr, S. L. Chen, S. Filippov et al., "Defect properties of $\mathrm{ZnO}$ nanowires revealed from an optically detected magnetic resonance study," Nanotechnology, vol. 24, no. 1, Article ID 015701, 2013.
[20] Q. Zhang, C. G. Tian, A. P. Wu et al., "A facile one-pot route for the controllable growth of small sized and well-dispersed $\mathrm{ZnO}$ particles on GO-derived graphene," Journal of Materials Chemistry, vol. 22, no. 23, pp. 11778-11784, 2012.

[21] J. Joo, B. Y. Chow, M. Prakash, E. S. Boyden, and J. M. Jacobson, "Face-selective electrostatic control of hydrothermal zinc oxide nanowire synthesis," Nature Materials, vol. 10, no. 8, pp. 596601, 2011.

[22] L. Sun, H. Shi, W. Li et al., "Lanthanum-doped ZnO quantum dots with greatly enhanced fluorescent quantum yield," Journal of Materials Chemistry, vol. 22, no. 17, pp. 8221-8227, 2012.

[23] N. P. Herring, K. Abouzeid, M. B. Mohamed, J. Pinsk, and M. S. El-Shall, "Formation mechanisms of gold-zinc oxide hexagonal nanopyramids by heterogeneous nucleation using microwave synthesis," Langmuir, vol. 27, no. 24, pp. 15146-15154, 2011.

[24] K. A. Alim, V. A. Fonoberov, M. Shamsa, and A. A. Balandin, "Micro-Raman investigation of optical phonons in $\mathrm{ZnO}$ nanocrystals," Journal of Applied Physics, vol. 97, no. 12, Article ID 124313, pp. 1-5, 2005.

[25] A. J. Reddy, M. K. Kokila, H. Nagabhushana et al., "Combustion synthesis, characterization and Raman studies of $\mathrm{ZnO}$ nanopowders," Spectrochimica Acta A, vol. 81, no. 1, pp. 53-58, 2011. 

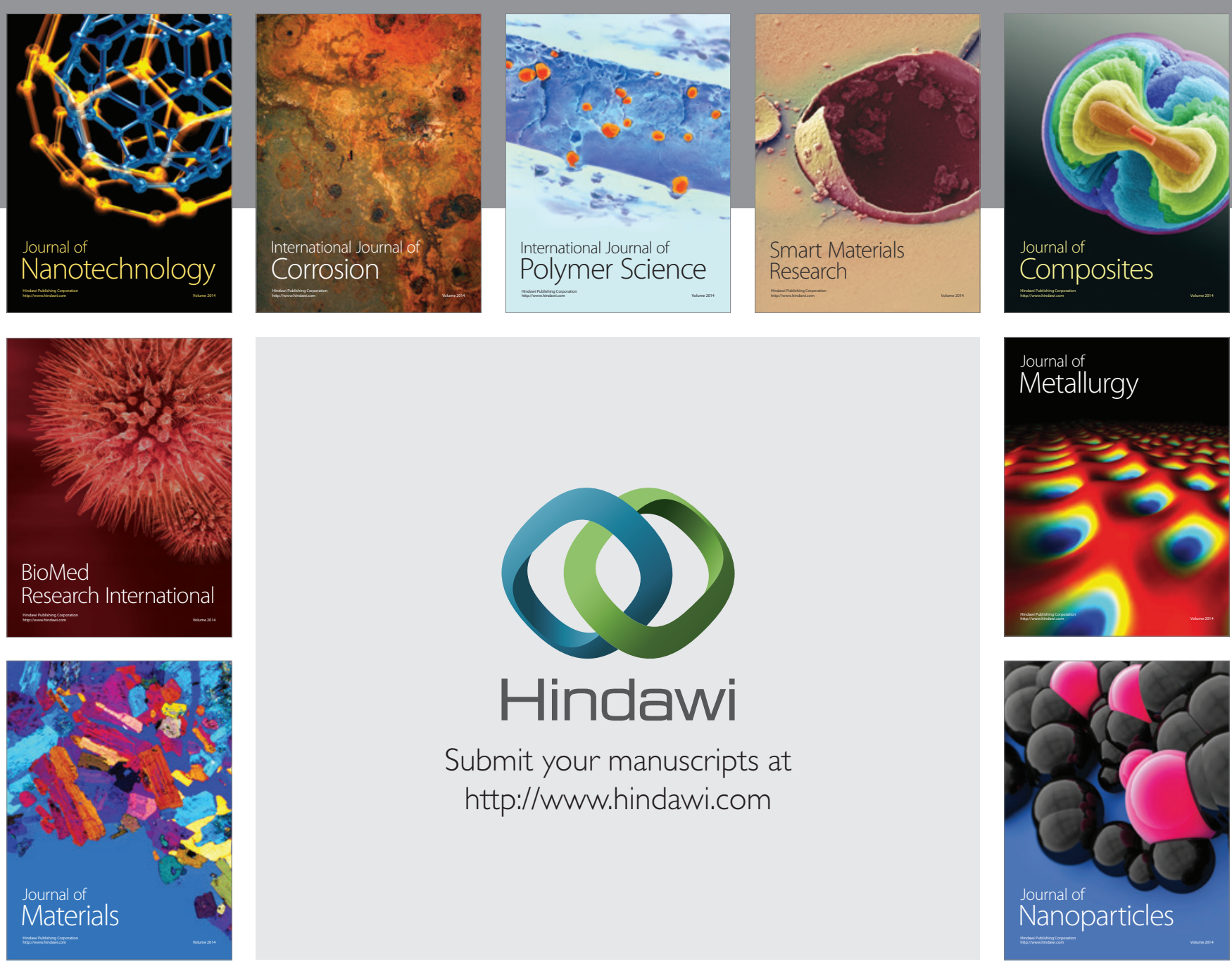

Submit your manuscripts at http://www.hindawi.com
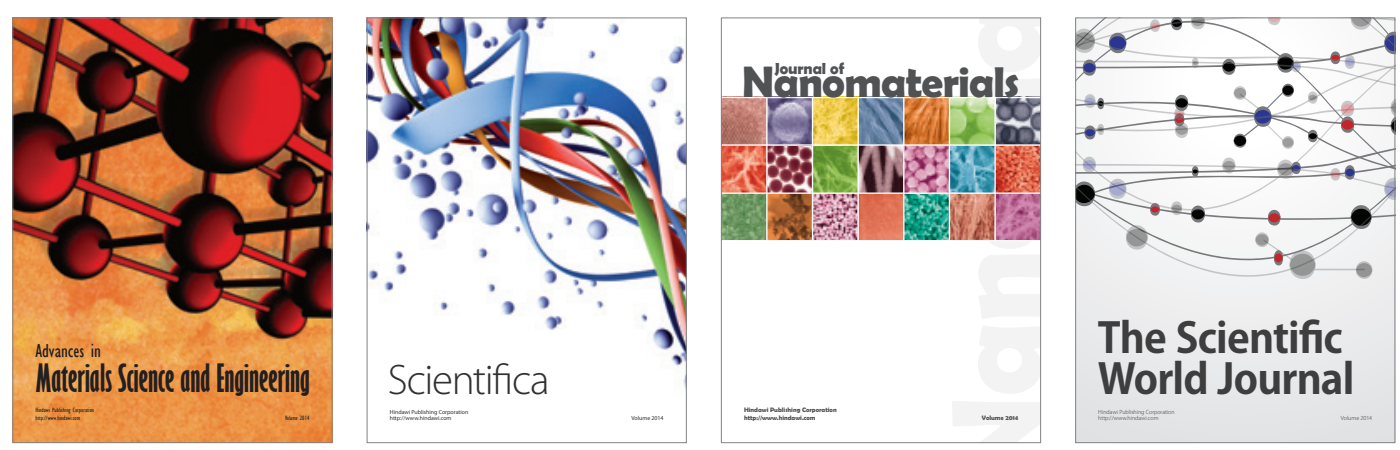

\section{The Scientific World Journal}
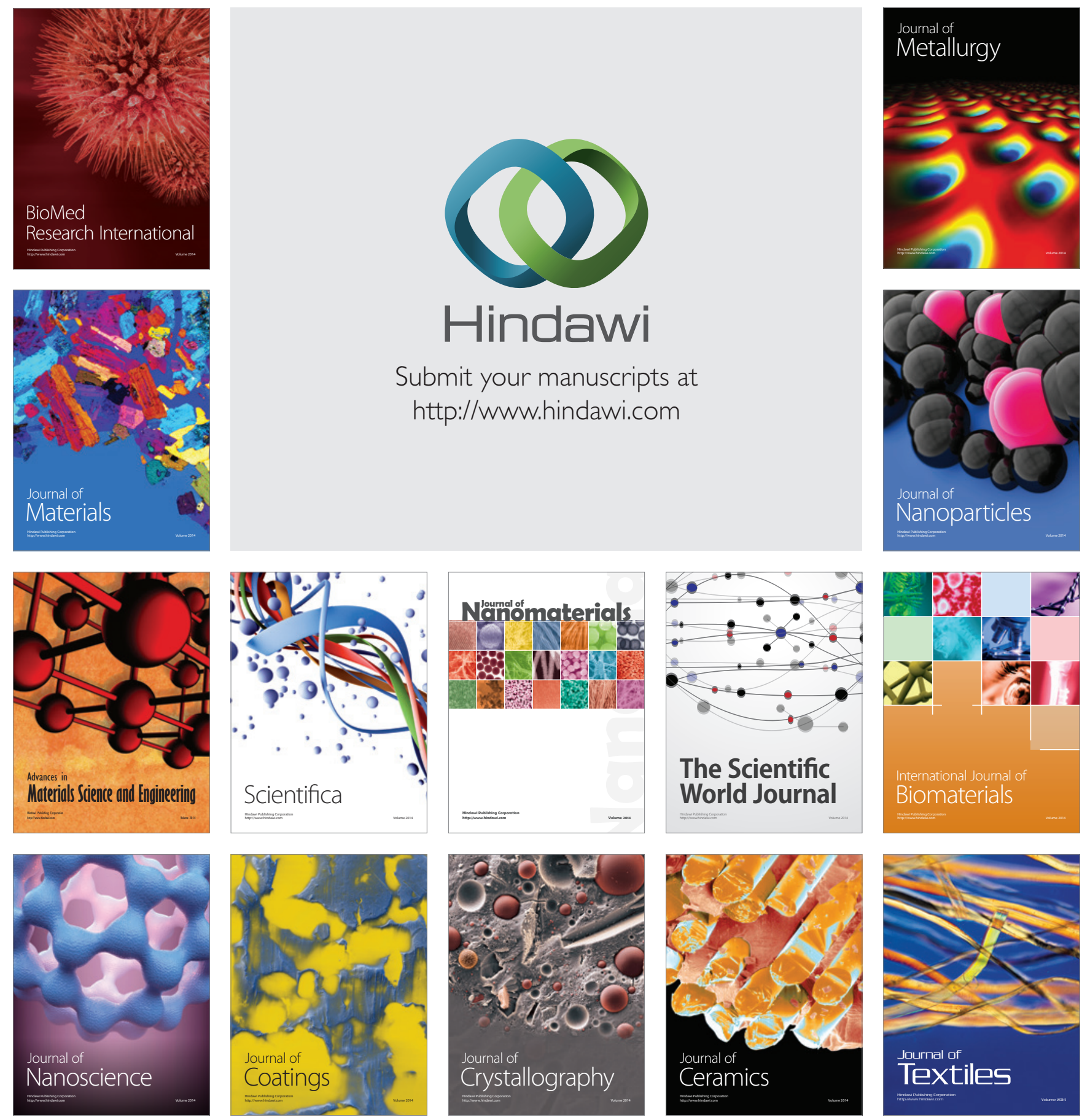